\title{
Al cap i a la fi, en fi $i$ en definitiva: tres marcadors discursius vehiculadors de la reformulació conclusiva en català
}

\author{
CARME BACH, UPF
}

\section{Introducció}

En aquest article analitzem el funcionament de tres marcadors discursius del català en textos escrits que comparteixen el fet que entre els seus components gramaticals hi ha la paraula fi: al cap i a la fi, en fi i en definitiva, per tal de ferne un estudi comparatiu.

Tot i que el grau de fixació d'aquestes unitats és elevat —es caracteritzen per la invariablilitat-, la presencia del mot $f i$ com a un dels seus elements constitutius influeix decididament en el funcionament semanticopragmàctic d'aquestes peces lèxiques, de manera que en aquests marcadors s'evidencia clarament una interrelació entre la forma i la funció. Tots tres marcadors esdevenen vehiculadors de la reformulació conclusiva en català ${ }^{1}$.

La reformulació és un mecanisme que permet a un parlant reprendre les seves pròpies paraules (autoreformulació) o les d'un altre (heteroreformulació) per tal de presentar-les des d'una altra perspectiva. Tradicionalment es distingeixen dos tipus de reformulació: la parafràstica i la no parafràstica (Gulich i Kotschi 1995, Rossari 1994).

Mentre que la reformulació parafràstica es defineix com a la relació d'equivalència semàntica que s'estableix entre dos enunciats (el reformulat i el reformulador), la reformulació no parafràstica es defineix com una relació de distanciament que s'estableix també entre l'enunciat reformulat i la seva nova formulació ${ }^{2}$.

Però com s'estableix aquesta relació d'equivalència/distanciament de què parlem?

${ }^{1}$ Cuenca (2002: 3199) inclou aquests marcadors en el grup dels consecutius, perquè a nivell procedimental vehiculen el significat de conclusió, a mig camí entre el valor additiu i disjuntiu que ella assenyala. Juntament amb els marcadors objecte d'estudi d'aquest article, també hi situa els marcadors en conclusió, al capdavall, total i tot plegat.

${ }^{2}$ Per estudiar amb més detall les diferències entre un tipus de reformulació i un altre en català, pot consultar-se Bach (2001: 209-244). 
D'una banda, en el cas de la reformulació parafràstica, la relació d'equivalència entre l'enunciat que es reformula i la seva nova formulació generalment ja és alt, de manera que només amb una pausa (en els textos orals) o amb una marca tipogràfica com ara una coma, un punt i coma, un punt o uns dos punts ja es dóna per establerta, encara que no és així en totes les ocasions.

D'altra banda, en el cas de la relació de distanciament ${ }^{3}$, serà sempre del tot necessària la presència d'un marcador reformulatiu no parafràstic perquè aquesta relació pugui establir-se i s'especifiqui clarament. Dins d'aquest grup trobem marcadors discursius com ara de fet, en realitat, de totes maneres, en tot cas, en qualsevol cas, en el fons i els marcadors objecte d'aquest estudi en fi, en definitiva i al cap $i$ a la fi.

En relació al distanciament vehiculat pels marcadors que analitzem, Gülich i Kotschi (1995) expliquen que el distanciament vehiculat per aquestes unitats no és uniforme sinó gradual, és a dir que hi ha marcadors reformulatius no parafràstics que estableixen un distanciament elevat entre els enunciats que connecten mentre que d'altres vehiculen un distanciament menor:

«Dissociations contain various degrees of distance, weak, medium or strong, which always remain below the level of an invalidation.» (Gülich i Kotschi, 1995: 50)

En aquest article, per a cada marcador, analitzarem: a) el grau distanciament que mantenen els enunciats connectats, b) les subinstruccions vehiculades per cada marcador, c) la jerarquia entre ambdós enunciats, d) la polifonia i, e) la posició sintacticodiscursiva. Finalment farem una anàlisi comparativa dels trets exposats anteriorment per a cada marcador.

\section{Al cap i a la fi (ACF)}

a) El distanciament entre els enunciats connectats establert per aquest marcador és en la majoria de les ocasions bastant baix, malgrat que es poden trobar alguns casos en què el distanciament vehiculat és elevat. Un exemple del poc distanciament que presenten els enunciats units per al cap i a la fi és ACF01:

Els grups musicals tocaven sota el tema «Tots valen», l'eslògan electoral que vol significar que tots els candidats a diputats del Parlament provincial i nacional són igualment vàlids.

Un concepte difícil d'entendre si es pensa en termes multipartidistes, però que aquí el mateix Fidel Castro ha explicat dient que «cal fugir de politiqueries i de lluites internes entre candidats». Al cap i a la fi, segons el comandant, tots defensen un projecte únic. (ACF01)

3 Tant l'establiment del distanciament com el de l'equivalència són operacions cognitives inherents a la humanitat, que per tal d'explicar el que veu, intenta classificar les coses com a iguals —equivalents—o com a diferents — distanciades. 
De l'enunciat «cal fugir de politiqueries i de lluites internes entre candidats» extraiem les conclusions que [menys importa el multipartidisme] [menys es volen fer unes eleccions legals][més control de les eleccions fa el règim cubà]. L'enunciat introduït per ACF va en la mateixa línia i Castro, a través del periodista, acaba justificant les seves pròpies paraules, amb la mateixa línia argumentativa que l'enunciat reformulat. Hi ha molt poc distanciament entre tots dos enunciats units per al cap i a la fi.

b) Juntament amb la reformulació — la funció bàsica vehiculada per aquest marcador-, la conclusió és la subinstrucció compartida per totes les ocurrències d'ACF analitzades, a causa del valor semàntic dels seus components. No només ens referim a la influència del mot $f i$ en el seu funcionament sinó que cal considerar que ACF està format per dos noms que expressen limitació espaciotemporal: cap i $f i^{4}$. ACF indica clarament un procés discursiu de reformulació que implica anar de dalt a baix del text i a la inversa, valorar els enunciats precedents i concloure una etapa discursiva mitjançant la reformulaciós ${ }^{5}$.

Paral-lelament a la conclusió, s'estableix una instrucció argumentativa en la majoria de les ocasions. De fet, aquesta és una instrucció que adquireix molta força en aquest marcador perquè s'utilitza en la legitimació argumentativa de l'enunciat que es reformula ${ }^{6}$.

En l'ocurrència que exposem a continuació, ACF argumenta a favor dels elements que es deriven del primer enunciat ${ }^{7}$ :

Durant dos dilluns seguits ens han volgut fer creure que això era Hollywood. Que havíem arribat a la majoria d'edat democràtica perquè ja fèiem com els nord-americans. Debats cara a cara entre els candidats a la presidència. A través de les televisions privades, naturalment. Que en les públiques uns no hi confien i els altres no creuen que els calgui defensar-les. Al cap i a la fi només en són administradors. (ACF02)

En aquesta ocasió el locutor presenta el primer enunciat del qual es podrien derivar topoi ${ }^{8}$ negatius si no comprenguéssim perquè els polítics no creuen que calgui defensar les televisions públiques. En el segon enunciat, segurament reprenent un argument utilitzat en algunes ocasions pel col-lectiu polític, s'argumenta a favor de la posició dels polítics que no es preocupen en excés de la televisió pública, perquè només en són mers «administradors».

${ }^{4}$ El diccionari Alcover-Moll indica que cap és una extremitat, en general on comença i acaba una cosa i que $f i$ és el punt o moment en què una cosa acaba o cessa.

${ }^{5}$ Creiem interessant assenyalar que el marcador paral-lel a ACF en castellà s'ha format amb els mateixos elements lèxics, encara que amb un ordre diferent: al fin y al cabo vs. al cap i a la fi.

${ }^{6}$ De fet, Montolío (1992: 459) assenyala això mateix per al marcador castellà al fin y al cabo.

7 És interessant assenyalar que Portolés (1998: 113) assenyala que el marcador castellà al fin $y$ al cabo vehicula sempre instruccions contraargumentatives. No hem trobat casos amb aquesta orientació en català.

${ }^{8}$ La noció de topoi, que s'extreu directament dels treballs de Ducrot i Anscombre (1983, 1995), és una de les eines metodològiques que utilitzem per a l'anàlisi dels marcadors que ens ocupen. 
Finalment, la instrucció de la continuació textual es fa també present en els casos en què el distanciament entre els enunciats connectats és més gran i el marcador s'utilitza en aquesta ocasió com una frontissa que facilita el canvi temàtic sense que es produeixi cap trencament en la línia argumental encetada per l'enunciat reformulat:

A l'Índia, al problema de manca de zones de conreu s'afegeix la salinització de la terra Només existeix una possible explicació per comprendre les actuacions econòmiques del Banc Mundial i rau en la pròpia subsistència d'aquesta institució. El BM funciona com una entitat de crèdit i finançament de grans plans d'inversió i desenvolupament. No finança projectes o obres menors. Al cap i a la $f i$, el Banc Mundial viu principalment de les contribucions dels països rics que sovint són els instigadors dels projectes i els primers a beneficiar-se'n. (ACF03)

En aquest text el locutor canvia de tòpic per encetar un nou tema; ja no és important si el BM finança projectes menors com els que caldria dur a terme sinó el fet que són els països rics els que hi fan les aportacions perquè funcioni i, evidentment, no perdran els seus diners ajudant ciutadans que no hi aporten res. Aquesta és la conclusió que introdueix el nou enunciat que es presenta.

c) El valor anafòric i jeràrquic del marcador es veu reforçat en aquest cas també pel contingut semàntic dels seus components lèxics. Qualsevol reformulació introduïda per al cap i a la fi esdevé definitiva respecte tot l'enunciat reformulat anteriorment, pel fet que la conclusió es fa fent una mirada general a l'enunciat reformulat, de dalt (cap) a baix (fi).

d) La polifonia també és present en tots els casos, malgrat que no sempre apareix formalment destacada: una nova veu es fa present com a executora de la reformulació conclusiva vehiculada.

e) Pel que fa al posicionament sintacticodiscursiu, ACF pot aparèixer després d'una pausa discursiva o juntament amb un altre marcador, quan actua com a connector entre dos enunciats; o com a mer operador discursiu, quan només s'utilitza per matisar aspectes de l'enunciat en què apareix.

Pel que fa a la seva combinabilitat amb altres marcadors, ACF apareix juntament amb perquè (ACF04), però (ACF05) i $i$ (ACF06).

La combinació amb perquè es veu afavorida pel fet que tots dos marcadors vehiculen una mateixa instrucció pragmàtica. Ambdues peces lèxiques estableixen una relació argumentativa coorientada entre els enunciats que uneixen, instrucció que en aquests casos es veu reforçada per la coocurrència d'ambdós marcadors:

La màxima intervenció de la indústria privada o pública en totes les fases és fonamental, perquè al cap i a la fi, serà l'encarregada de comercialitzar el producte obtingut. (ACF04)

En aquest exemple es pot veure clarament com els dos nexes - perquè i al cap $i$ al fi- introdueixen una justificació argumentativa del primer enunciat. $\mathrm{ACF}$, a més a més, vehicula una reformulació de la frase «La màxima interven- 
ció de la indústria privada o pública en totes les fases és fonamental», a tall de reavaluació distanciadora.

$\mathrm{Al}$ contrari, quan ACF es combina amb però, la peça lèxica que ens ocupa no comparteix les instruccions del connector contraargumentatiu sinó que es veu com l'enunciat reformulador es presenta com una justificació de l'enunciat anterior, amb el qual sembla voler contraargumentar el locutor, encara que en realitat no ho faci:

A França, que és una democràcia més antiga i més sàvia que la nostra, ningú no amaga que el fet que els alcaldes de les grans ciutats siguin, alhora, diputats és una manera com una altra de fer pressió sobre les decisions del govern central. Aquí, ens omplim la boca parlant de la unitat d'Espanya, però, al cap i a la $f i$, existeixen els mateixos «lobbies» territorials que en altres països sense, però, reconèixer-ho, que és una manera molt quixotesca d'anar pel món. València, durant tots aquests anys, no ha tingut un «lobby» propi a Madrid com l'han tingut Andalusia i la mateixa ciutat de Madrid i — d'una altra maneratambé Catalunya, Euskadi i Galícia. Hi ha un cert interès a mantenir una societat valenciana desvertebrada; potser perquè és rica i aporta molts diners a l'erari estatal. (ACF05)

Si bé en primer lloc sembla que l'enunciat «però, al cap i a la fi, existeixen els mateixos «lobbies» territorials que en altres països» s'oposi a l'enunciat anterior, veiem que en realitat, gràcies a la reformulació introduïda per $\mathrm{ACF}$, aquest enunciat el justifica ja que ambdós convoquen topoi concordants [com més ens omplim la boca parlant d'una cosa] [més fals és que ens ho creiem o que sigui veritat]. L'enunciat reformulador corrobora aquest topos explicitant informació que, com a receptors del text, podíem desconèixer: «existeixen els mateixos lobbies que en d'altres països, però no es volen reconèixer».

Finalment, la combinació amb l'arxiconnector $i$ també apareix en el nostre corpus d'anàlisi. Aquesta combinació és possible pel fet que en aquests casos ambdós nexes coincideixen en la funció d'introduir nous elements argumentatius amb la mateixa orientació que la de l'enunciat que precedeixen:

Després de la crisi del Líban, Zapatero no es pot permetre més Moratinos. Excepte que opti per un suïcidi polític: convertir la política exterior espanyola en una sucursal europea dels populismes americans i convertir-se ell mateix en un Hugo Chávez amb corbata. Si no vol això, si vol normalitzar les relacions amb els Estats Units, si vol ser un líder europeu normal, Zapatero haurà de prescindir de Moratinos. Certament, amb això Moratinos pagarà alguns errors i algunes ficades de pota del mateix Zapatero. Però això no ha de fer patir el president del govern espanyol. També pagarà Moratinos els errors propis. I al cap i a la fi la seva feina era cobrir l'esquena del seu cap. No pas empentar-lo per l'esquena. (ACF06)

En aquest cas a través de la conclusió continuativa introduïda per $i$ al cap i a la fi se'ns explica i justifica la substitució de Moratinos del govern Zapatero perquè el que havia de fer era vigilar que el govern de Zapatero no fes relliscades en el camp internacional i no ho va fer bé. 


\section{3. en fi (ENF)}

a) El distanciament entre els enunciats units per en fi és molt baix en la majoria de les ocasions, excepte en els casos en què s'introdueixen elements tematicoargumentatius nous al text:

Els escriptors blancs havien creat barreres artificials, considerant que la literatura negra i la blanca eren coses separades. Ara poden imaginar personatges negres, poden experimentar i plantejar-se nous llenguatges; en fi, poden absorbir completament les influències de la cultura negra. I això, que era un factor visible en la música i el cinema, es comença a veure ara també en la literatura. (ENF01)

Del primer enunciat podem extreure els següents topoi: [com més nous llenguatges i més canvis poden experimentar els escriptors] [més obertura cap el món exterior hi ha]. La conclusió recapitulativa que introdueix en fi marca, clarament, que aquesta obertura es limita a l'absorció de la cultura literària negra. Fins i tot podríem commutar el marcador en fi per és a dir, el qual realitzaria en aquest cas les mateixes funcions que en fi, excepte que en lloc d'indicar una relació de distanciament marcaria una relació d'equivalència.

b) La conclusió és la instrucció vehiculada per aquest marcador en tots els textos analitzats. El mot $f i$ indica un acabament, una reformulació conclusiva que aquesta peça lèxica vehicula en totes les ocasions. En comparació amb d'altres llengües romàniques, com ara el francès (enfin) o el castellà (en fin), diversos autors (Adam i Revaz 1989, Luscher i Moeschler 1990, Grieve 1996 - per al francès—i Portolés 1998 - per al castellà-) assenyalen que en aquestes llengües i per aquesta peça lèxica s'observen dos valors principals: el temporal, d'una banda, i el reformulatiu, de l'altra. En canvi, altres estudis (Cadiot et al. 1985 i Franckel 1987) coincideixen amb el que hem observat per al català: l'únic valor actiu és el reformulatiu. Creiem que l'evolució pragmàtica d'aquest marcador en català l'ha fet passar del valor bàsicament temporal a l'actual reformulatiu i conclusiu.

A través d'ENF, s'estableixen altres matisos instruccionals que no són compartits per totes les ocurrències analitzades. Així, la conclusió que s'estableix pot ser enumerativa —quan s'introdueix el darrer argument d'una sèrie (ENF02)-, pròpiament argumentativa — quan s'introdueix un argument nou que aclareix elements anteriors que en algunes ocasions restaven implícits (ENF03) capitulativa - quan l'enunciat que conclou es presenta com un resum argumentatiu dels enunciats connectats (ENF04)—, a voltes a més a més amb matisos denominatius (ENF05) i, finalment, de continuació textual — quan es tanca un grup argumental i se n'obre un altre de diferent (ENF06) ${ }^{9}$.

${ }^{9}$ Alguns treballs en francès i castellà assenyalen que enfin/en fin pot tenir un valor instruccional correctiu. Nosaltres no hem trobat que aquesta instrucció fos vehiculada en cap de les ocurrències analitzades. 
L'anàlisi detallada d'algunes de les ocurrències a què acabem de referir-nos servirà per exemplificar la casuística d'aquesta peça lèxica.

En l'exemple que tot seguit comentem, trobem el marcador en un text d'economia en què el locutor fa una exposició a tall d'enumeració per explicar-nos quins tipus d'empresa poden existir:

L'empresa pot fer un sol producte o servei, o bé molts productes i serveis alhora (i en aquest cas es parla de producció conjunta); pot controlar una sola, o moltes instal-lacions productives; pot desenvolupar l'activitat en un sol país, o en diversos països (empresa multinacional: vegeu, a més a més, pàg. 136). En fi, l'empresa pot ser propietat privada (empresa privada), o bé de l'Estat o d'ens públics (empresa pública). (ENF02)

Segons el locutor poden tipificar-se empreses «de producció única o conjunta», «d'una instal-lació única o amb moltes instal-lacions productives», «nacional o multinacional» i, finalment, «privades o públiques». En aquesta ocasió, ENF introdueix el darrer element d'aquesta enumeració i es tanca així el fil tematicoargumentatiu iniciat. Creiem que el valor enumeratiu és el que està més directament relacionat amb el seu ús temporal primitiu, ja que en certa manera també marca l'ordre dels esdeveniments.

En la següent ocurrència el marcador s'utilitza per introduir l'explicitació dels elements argumentatius que quedaven implícits en el primer enunciat:

El cas subratlla, també, els límits modernitzadors del darrer decenni: com és possible que en la línia més antiga de la Península, inaugurada el 1848, que dins d'una conurbació de tres milions d'habitants i a cinc minuts del futurisme de la Vila Olímpica hi hagi encara una pila de passos a nivell amb campana i barreres? És que la tecnologia que aixecà la Torre de Collserola o el Palau Sant Jordi no permet suprimir-los? En fi, l'afer confirma l'habitual impunitat dels errors polítics, o amb implicacions polítiques: consumada la pífia, ningú —des de la presidenta Mercè Sala fins a l'últim tècnic de la «Quinta Zona» de Renfe-, ningú no ha donat cap explicació pública satisfactòria ni, menys encara, ha posat el càrrec a disposició de la superioritat. (ENF03)

Del primer enunciat, de forma implícita, i sempre que compartim l'univers de creences en què se situa el productor del text, podem concloure el que diu clarament l'enunciat reformulador: [com més escandalós és l'endarreriment tecnològic en un determinat camp de competència pública] [més es confirma la impunitat dels polítics en relació amb els seus errors de gestió] i [més necessària seria la seva dimissió].

En altres ocasions, la conclusió introduïda per ENF és de caràcter recapitulatiu quan es redueixen tots els arguments presentats anteriorment a un de sol que es presenta jeràrquicament com a molt més important que la resta, gràcies a la reformulació, en el sentit que el locutor vol fer entendre que l'única cosa rellevant del seu discurs és la que comunica l'enunciat reformulat. L'ocurrència ENF04 és un exemple evident del que acabem d'exposar: 
Però, tot i que era molt senzill i en conseqüència no estava pas equipat amb tota la maquinària necessària, si s'espavilaven podien fer entre tots unes dotze lliures d'agulles al dia. En una lliura hi entren més de quatre mil agulles de mida mitjana. Per tant, entre totes aquestes persones podien fer més de quaranta-vuit mil agulles en un sol dia. Es pot considerar, doncs, que si cada persona feia una desena part d'aquestes quaranta-vuit mil agulles, cadascuna d'elles feia quatre mil vuit-centes agulles de cap al dia. Però si tots haguessin treballat separats, cadascun pel seu compte, sense haver estat ensinistrats per a aquest ofici particular, és evident que no n'haurien pogut fer vint, i potser ni una sola en un dia; en fi, és segur que no n'haurien pogut fer la dues-centes quarantena, ni potser la quatre mil vuit-centena part del que avui són capaços de produir, gràcies a una divisió adequada i a la combinació de totes les diferents operacions. (ENF04)

En aquest cas, la sèrie d'enunciats que precedeixen el marcador, «tots haguessin treballat separats, cadascun pel seu compte, sense haver estat ensinistrats per a aquest ofici particular, és evident que no n'haurien pogut fer vint, i potser ni una sola en un dia», porta a concloure que la divisió del treball ha estat essencial per a l'avanç econòmic i social de la producció empresarial, amb una reducció clara del contingut informatiu i argumentatiu del primer enunciat.

En altres ocasions, la reducció establerta per ENF és clarament de caràcter denominatiu, com succeeix en el fragment que presentem a continuació, en què tot l'enunciat precedent es reformula en un sol terme:

En canvi, les sancions administratives són conseqüència de la comissió d'una infracció administrativa. Constitueixen, doncs, una repressió, pressuposen la realització d'un comportament prohibit i representen, en fi, un posterius», J. Suay Rincón, Sanciones..., op. cit., pàg. 64. (ENF05)

En aquesta ocasió, l'autor condensa l'enunciat reformulat en un terme posterius, de manera que podem parlar de denominació, malgrat un distanciament mínim establert pel marcador en fi. Aquesta reformulació podria vehicular-se mitjançant alguns marcadors reformulatius parafràstics com ara dit d' una altra manera, és a dir, en altres paraules, i malgrat les diferències que s'evidenciarien pel canvi de marcador, el matís denominatiu seguiria sent el mateix. Volem assenyalar en aquest cas la rellevància jeràrquica del segon enunciat, que es reforça a través de la referència polifònica a l'autoritat: «representen, en fi, un posterius, J. Suay Rincón, Sanciones..., op. cit., pàg. 64.»

Finalment, ENF s'utilitza com a marcador de l'estructura lineal del text (Turco i Coltier 1988), com a continuador textual, quan es clou un enunciat i se n'inicia un altre de temàticament nou:

En Francesc Tasies, que confia a diversos tallers la manufactura de les seves espardenyes, explica que el millor cànem del món es collia a Balaguer, però que ara ja no n'hi ha. Aquest any l'han comprat a Romania i diu que potser l'any que ve hauran d'anar-lo a buscar a l'Índia, en fi, coses del negoci. (ENF06) 
En aquesta ocasió, el locutor ens indica que hi ha hagut canvis en la qualitat del cànem que afecten la producció d'espardenyes. D'aquest enunciat es podrien derivar diverses conclusions, però a l'enunciat reformulador es tallen totes les possibles inferències que es podien extreure i s'introdueix un element temàtic nou: en el món dels negocis cal saber adaptar-se constantment si es vol tirar endavant.

c) ENF no vehicula la jerarquia entre els enunciats units en totes les ocasions, encara que sí que l'estableix en la majoria de les ocurrències analitzades. Atribuïm aquesta particularitat funcional del marcador a la seva composició semàntica. El fet de marcar la fi d'un fil temàtic no implica que aquest acabament hagi de ser necessàriament més important que l'anterior. Així, en els casos en què es vehicula una conclusió enumerativa, l'enunciat reformulador no es presenta com a més important, sinó que s'equipara amb els anteriors.

d) La polifonia sí que es fa present en tots els casos, encara que només en algunes ocasions apareix clarament marcada tipogràficament mitjançant la interrogació, la cursiva o les cometes tipogràfiques:

Potser tenia raó el gran Gustave Flaubert quan, en unes pàgines del seu epistolari, deia, a propòsit del paper que hauria de tenir en una societat la gent il-lustrada: «Em sembla que la massa, el ramat, sempre serà odiable [ ]. Mentre la gent no s'inclini davant aquest estol de mandarins, la política i la societat no seran res més que un feix de ximpleries repugnants». En fi, pensem-hi. (ENF07)

e) En referència a la seva posició en el discurs escrit, cal assenyalar que aquest marcador apareix després d'una pausa marcada o bé amb un punt, amb un punt i coma o amb una coma en la majoria de les ocasions, excepte en els casos en què es combina amb altres unitats connectives.

A més a més, cal indicar que aquest marcador es pot situar també al final d'un element discursiu deixant la reformulació oberta al lector. És el cas de l'ocurrència ENF08 del nostre corpus:

En termes econòmics, una pista d'esquí no és rendible. Cada hivern, però, són més i més les estacions hivernals que s'obren. Què passa, doncs?: la construcció d'urbanitzacions, hotels, pubs i restaurants a prop de les pistes, això sí que dóna molts diners. No tenim res contra els ciutadans que es diverteixen lliscant amunt $i$ avall per la neu. Recorren tres-cents metres i altra vegada agafen el telesquí per tornar a baixar.

Enfi...

El que no acceptem, però, en cap moment, és que aquesta pràctica esportiva que podria ajudar a estrènyer els vincles entre l'home i la natura es realitzi a costa de la tala d'arbres per a obrir les pistes i de la destrucció de l'equilibri de la natura per a instal-lar xalets i hotels. (ENF08)

En aquesta ocasió, el locutor utilitza la peça lèxica ENF per tancar una sequiència tematicoargumentativa anterior i encetar-ne una de nova, mitjançant un 
moviment permutant en què es vehicula una instrucció de continuació textual clara $^{10}$.

En referència amb la possible combinabilitat d'ENF amb altres nexes discursius, trobem casos en què aquesta peça lèxica va precedida de l'arxiconnector $i$ - en casos en els quals a través de la reformulació s'afegeix un element nou a l'argumentació iniciada (ENF09)—, i també s'observa la combinació amb però —en casos en què el locutor l'utilitza per reforçar clarament el canvi d'elements tematicoargumentatius anteriors (ENF10):

Deia que l'economia no és sinó l'estudi de la humanitat en el seu comportament en la vida de cada dia. Jo hi afegiria l'estudi del paper de les organitzacions, de la manera com els homes han de recórrer a les grans empreses, als sindicats i als governs per tal de satisfer les seves necessitats econòmiques; l'estudi dels fins que es proposen aquestes organitzacions en la mesura que coincideixen o s'oposen a l'interès general. I, en fi, de com fer prevaler l'interès de la col-lectivitat. (ENF09)

Amb els seus exagerats desplegaments dialèctics, estan quedant en evidència davant del comú de la gent que viu la política sense el fonamentalisme partidista que en un i altre bàndol, un dia sí i l'altre també, no paren de corrompre - perillosament-el millor llegat de la transició: l'esperit de tolerància, la base mateixa de la convivència. Però, en fi, aquest és un altre afer sobre el que haurem de tornar en dies futurs; avui, el nostre principal afany passa per alertar sobre el perill que suposa per als nostres camperols ser a la llista de Fischler. (ENF10)

\section{En definitiva (EDF)}

a) El distanciament establert per aquest marcador és discret en la majoria dels casos encara que en alguna ocasió pot ser elevat, quan el marcador vehicula una instrucció de continuació textual, en què el marcador actua a mode de permuta.

b) El marcador EDF comparteix en tots els casos una mateixa instrucció de segon nivell que és la conclusió, influïda pel fet que en definitiva també està format sobre el mot fi. A més a més de la conclusió, es vehiculen en paral-lel i a vegades de forma simultània, instruccions recapitulatives (EDF01), argumentatives coorientades (EDF02), designatives (EDF03) i instruccions de continuació textual, en què es produeix un canvi en la trajectòria tematicoargumentativa del text $(\mathrm{EDF} 04)^{11}$ :

${ }^{10}$ Nosaltres creiem que en aquests casos la reformulació el locutor la deixa oberta al receptor. En l'anàlisi del marcador paral-lel castellà, Vázquez (1994: 379) indica que aquest ús està relacionat amb la instrucció de resignació. Tot i que veiem possible aquesta interpretació, ens sembla més coherent seguir-lo tractant com a reformulador conclusiu de continuació textual, perquè al cap i a la fi el que es fa amb la reformulació, tant si és o no per resignació, és encetar un nou fil tematicoargumentatiu.

${ }^{11}$ Pel que fa al francès, Roulet (1987a i 1987b) indica que el marcador en définitive pot vehicular instruccions argumentatives tant orientades com antiorientades. Pel que fa al marcador que ens ocupa, no hem observat en català la possibilitat que vehiculi instruccions contraargumentatives. 
L'estiu i la tardor són els períodes de màxima productivitat biològica d'aquests estanys. Un màxim relatiu, és clar, que no supera el dels deserts freds de la Terra. És curiós, però les densitats de plàncton més importants es donen a fondàries de l'ordre dels 30 metres, profunditat accessible a la llum només gràcies a l'extrema transparència de les aigües: la vida en aquests estanys, doncs, es concentra aigües ensota. En definitiva, un àmbit singular i fràgil que demana ser tractat amb delicadesa i respecte. (EDF01)

Veiem que en aquest cas, a través del marcador s'introdueix un conclusió recapitulativa: de l'enunciat anterior «la vida en aquests estanys, doncs, es concentra aigües ensota» podem extreure conclusions com ara [com més amunt ens situem] [menys vida hi ha], [com més amunt de l'estany] [menys condicions òptimes hi ha perquè hi hagi vida] i també [com més avall estem] [més cal tenir cura de l'espai si volem mantenir-lo]. A través de la reformulació els topoi que s'inferien es redueixen a un de sol, de mode que la reformulació esdevé clarament recapitulativa.

En la següent ocurrència, el marcador EDF estableix una instrucció de recapitulació dels elements enunciatius que apareixien en el primer enunciat connectat, que esdevé alhora una argumentació orientada respecte als elements enunciatius reformulats:

Una aproximació general ens mostrarà que la publicitat és un instrument inherent a l'economia de mercat: és un importantíssim factor econòmic, ja que mou grans xifres a tot el món occidental; és, sense cap mena de dubte, el condicionant directe més ostensible del consum, és un importantíssim vehicle de comunicació social i un dels signes rellevants de la cultura del nostre temps. És, en definitiva, un producte de la civilització. (EDF02)

Del primer enunciat, «la publicitat és un instrument inherent a l'economia de mercat: és un importantíssim factor econòmic (...) és, sense cap mena de dubte, el condicionant directe més ostensible del consum, és un importantíssim vehicle de comunicació social i un dels signes rellevants de la cultura del nostre temps», concloem necessàriament que la publicitat té un valor essencial en la nostra societat. Aquesta conclusió es veu reduïda a un sol enunciat i reforçada argumentativament per la recapitulació: la publicitat esdevé tan important en la nostra societat que es presenta directament com «un producte de la civilització».

Creiem que les unitats geogràfiques dels Països Catalans haurien de constituir cada una d'elles una Coordinadora Nacional que mantingués contacte constant amb els Països germans tant per estructurar estratègies conjuntes com per passar-se informacions, com per demostrar-se una solidaritat activa i fins i tot per atrevir-se a traçar una alternativa de nou model de societat per als Països Catalans i les formes amb què cadascuna de les economies podria relacionarse. En definitiva, donar la resposta ecologista a la crisi actual. (EDF03)

En aquest text es reformula tota l'oració anterior en què se'ns diu que cal estructurar estratègies conjuntes per traçar una alternativa al nou model de societat 
i a les formes de relacionar-se de les economies. La reformulació introduïda per l'autor del text esdevé conclusiva i també designativa en certa manera ja que la conclusió del text és l'explicació a mode de definició enciclopèdica del que vol dir atrevir-se a traçar un nou model de societat en què totes les economies puguin relacionar-se.

Finalment, en el text següent, el marcador introdueix un element nou en el discurs que no té una relació ni argumentativa ni discursiva directa amb el discurs anterior:

L'optimització d'aquesta fracció de cabal admès en el bescanviador, es fa comparant globalment les despeses d'inversió i d'explotació del bescanviador.

A igualtat de potència, el preu del bescanviador té tendència a minvar quan el cabal del secundari augmenta; per altra banda, els costos dels elements auxiliars (bombes, canonades, etc...), les despeses d'electricitat, etc., augmenten.

L'òptim se situa al voltant del 110 al 125\% del cabal del primari.

La funció bàsica del bescanviador consisteix en permetre l'intercanvi de calor entre el fluid geotermal (salí i corrosiu) i el que circula pel circuit secundari. Així, per aquest circuit, on es troba a més a més el sistema de recolzament (caldera, bomba de calor, etc.), hi circularà un fluid de bona qualitat química.

L'únic problema que es presentarà, en definitiva, serà el de la corrosió metàl-lica en el circuit primari, per on circula el fluid geotermal. Si aquest fluid és agressiu, el circuit primari haurà d'ésser construït amb ferro fos amb aliatge, resines amb fibra de vidre o aliatges de titani. (EDF04)

En el primer enunciat es presenta la complexitat del sistema de funcionament d'un by-pass (bescanviador de calor geotèrmica). D'aquest primer enunciat podem derivar entre d'altres conclusions que, [com més complex és el sistema] [més car és el manteniment], però no podem concloure que comportarà «un únic problema» que serà «la corrosió metàl-lica». D'aquesta manera el locutor introdueix un element nou al text i per vincular-lo amb l'enunciat anterior utilitza el marcador EDF com si aquest nou argument pogués derivar-se del text anterior.

c) El valor anafòric i jeràrquic establert per aquesta peça lèxica és evident, fet que atribuïm també a la seva composició. El caràcter díctic es fonamenta en el valor conclusiu vehiculat pel morfema $f i$, que necessàriament fa referència a un discurs anterior. El valor jeràrquic de l'enunciat reformulador ve reforçat per la situació del locutor en una posició privilegiada en el discurs, des de la qual pot extreure conclusions rellevants.

d) La presència de polifonia en aquest marcador és destacada perquè s'intueix clarament la presència de dos locutors enunciatius diferents en el text: el que produeix el primer enunciat i el que en presenta les conclusions. De totes maneres, aquesta polifonia es fa només explícita clarament en el text en algunes ocasions, mitjançant les cometes tipogràfiques i fins i tot amb el canvi de llengua, com pot observar-se en el següent text: 
El precepte fou recorregut pel govern de la Generalitat, en base a argumentacions situades en la línia d'allò que queda exposat abans. Però el TC, en una sentència sorprenent, manté el text d'aquell article 22, tot diferenciant el concepte de nomenament del d'oposició i concurs, en la forma següent:

«De la lectura del precepto (EAC, 24) se desprende que la competencia —que se sitúa dentro del marco de las competencias de ejecución- que el Estatuto atribuye a la Generalidad, es la de efectuar el nombramiento de los Notarios con arreglo a las leyes del Estado y que, aún cuando alude a algunas peculiaridades que deben existir en los concursos y en las oposiciones para cubrir plazas del territorio de Catalunya no atribuye a la Generalidad la competencia respecto de estos concursos y oposiciones. De esta suerte debemos concluir que en la interpretación del art. 24 del Estatuto de Cataluña nombramiento debe entenderse como concreta designación. Hay toda una serie de argumentos que conducen a esta conclusión. No es sólo ese el alcance que la expresión tiene en el lenguaje espontáneo. Además, hay argumentos de orden histórico y sistemático en favor de la misma solución. El hecho de que el artículo 24 del Estatuto de Autonomia de 1979, encuadrado en el marco de la Constitución de 1978, contraste con el Estatuto de 1932 que fue derivación de la Constitución de 1931, parece indicio suficiente de la voluntad del legislador de limitar la intervención de la Comunidad Autónoma de Cataluña en relación con los Notarios. Y no se nos diga que de esta manera se vacía la competencia de la Generalidad de Cataluña, pues aparte de que es la que el Estatuto asumió resulta una potestad pública de indudable trascendencia, ya que supone la específica habilitación para el ejercicio de la función en la plaza y cargo». En definitiva, el precepte impugnat és declarat constitucional, amb una sola particularitat: es refusa la preferència de la publicació en el BOE i s'estableix l'equiparació entre aquesta publicació i la del DOGC. (EDF05)

e) Finalment, ens referim a la possibilitat combinatòria d'aquesta peça lèxica amb altres marcadors i a la seva situació en el discurs. Si no es combina amb altres marcadors, EDF apareix habitualment després d'una pausa discursiva marcada per una coma o un punt ${ }^{12}$.

Quan es combina amb altres marcadors, EDF apareix amb l'arxiconnector $i$ (EDF06), en casos en què s'amplien els elements argumentatius del primer enunciat; amb el marcador perquè, quan es conclou amb un matís argumental important $(\mathrm{EDF} 07)^{13}$, i també amb el marcador adversatiu per excel-lència però (EDF08).

L'especialització en la producció i la diversificació en el consum generen la necessitat d'intercanvi i, en definitiva, la inevitabilitat de la interacció entre els diferents agents. (EDF06)

${ }^{12}$ Creiem que en la llengua oral sempre hi ha una mínima pausa entre l'enuncitat reformulat $\mathrm{i}$ el marcador EDF, que acostuma a marcar-se en els textos escrits, encara que no en totes les ocurrències analitzades.

${ }_{13}$ Aquesta és una nova possibilitat de combinació que no assenyalàvem a Bach (2001), que es veu afavorida pel fet que en aquest article no fem distinció entre connectors i marcadors discursius. 
Necessitat d'intercanvi és presentada com un terme que pot ser definit en el llenguatge especialitzat de l'economia en termes d'interacció inevitable entre tots els agents, mitjançant el procés reformulatiu vehiculat per en definitiva, i es reforça alhora el valor de la designació pel caràcter d'argument de l'enunciat reformulat. Convé destacar que en definitiva vehicula en aquesta ocasió un grau elevat de consens, 'definitiu' per als especialistes als quals va dirigit el text.

Una de les coses que m'ha agradat més aquests últims dies és el cartell que presenta Montilla com un home de fets, no de paraules. És cert que és un personatge desconegut, però allà on ha estat ha donat resultats i per aquest motiu aquest país necessita deixar de dir que vol passar a l'acció per passar a l'acció i en Montilla és l'únic candidat que ho pot realitzar. Perquè, en definitiva, necessitem continuar tenint un govern que mentre els altres parlen ells treballin a favor de les persones. (EDF07)

En aquest cas, podríem treure el perquè i l'enunciat continuaria tenint la força conclusivoargumentativa que ve vehiculada pel marcador en definitiva. El que segons el locutor de l'enunciat reformulat és important per Catalunya és que es treballi a favor de les persones.

Durant el període de 1931-33 la indústria de béns de consum havia experimentat, a diferència de la d'inversió un fort auge. La minva de l'atur i les alces salarials comportaren un fort increment en la demanda d'aquesta indústria. Però arran del 1934 la reducció salarial duta a terme pel nou Govern i l'espectre de l'atur l'afectaren greument. Però, al costat de tots aquests factors econòmics interns, als quals s'uneixen els polítics i socials, desencadenants de la crisi espanyola dels anys 30, caldria destacar-ne també, encara que en un pla secundari, els externs, és a dir, la repercussió de la crisi econòmica internacional. Aquest fet queda reflectit en la caiguda del comerç exterior com a conseqüència de la política de defensa de la producció nacional, desenvolupada pels diferents països per mitjà de l'elevació de les barreres aranzelàries. Però, en definitiva, el que es tracta de posar en relleu és la greu crisi de l'economia espanyola als anys 30. Com hem vist, són les empreses pertinents al sector industrial de béns de producció aquelles que sofreixen la recessió més aviat, donat el doble efecte produït per la minva i pel canvi de sentit de la inversió pública i les alces salarials; i en un pla força menor, com a conseqüència de la deterioració del comerç exterior, ja que el percentatge de producció d'aquestes empreses destinades al mercat exterior era reduït. (EDF08)

En aquesta ocasió ens trobem amb un fragment sobre la història econòmica espanyola als anys 30 . El locutor de l'enunciat reformulador canvia el gir de l'enunciat reformulat, en què hi havia una narració dels fets econòmics per concloure dient-nos que tot això era perquè entenguéssim com de greu era la crisi econòmica dels anys 30 . Concorda amb però perquè es produeix una clara operació de gir tematicoargumentatiu del text. 


\section{Conclusions}

Volem acabar aquest article amb la comparació dels tres marcadors que hem analitzat en deteniment, al cap i a la fi, en fi i en definitiva.

Pel que fa al grau de distanciament vehiculat pels marcadors que ens ocupen cal dir que en la majoria de les ocasions és elevat excepte en els casos en què vehiculen instruccions de continuació textual, en què es produeix un gir en els arguments aportats per l'enunciat que es reformula.

En relació a les instruccions vehiculades per cada marcador, és interessant assenyalar que no només la reformulació i la conclusió són compartides per tots els marcadors que hem analitzat, sinó que també la continuació textual i l'argumentació són vehiculades pels tres marcadors objecte d'aquest estudi (vegeu quadre 1):

\begin{tabular}{|l|l|}
\hline Conclusió & $\begin{array}{l}\text { al cap i a la fi } \\
\text { en fi } \\
\text { en definitiva }\end{array}$ \\
\hline Continuació textual & $\begin{array}{l}\text { al cap i a la fi } \\
\text { en fi } \\
\text { en definitiva }\end{array}$ \\
\hline Argumentació & $\begin{array}{l}\text { al cap i a la fi } \\
\text { en fi } \\
\text { en definitiva }\end{array}$ \\
\hline Recapitulació & $\begin{array}{l}\text { en fi } \\
\text { en definitiva }\end{array}$ \\
\hline Designació & en definitiva \\
\hline Denominació & en fi \\
\hline Enumeració & en fi \\
\hline
\end{tabular}

QUADRE 1. Subinstruccions vehiculades pels marcadors objecte d'estudi d'aquest treball.

Si analitzem amb més detall el quadre anterior, podem observar que el marcador al cap i a la fi no vehicula instruccions diferents a les dels altres marcadors estudiats.

D'una banda, podem inferir que instruccionalment al cap $i$ a la fi podria ser substituït per en fi i en definitiva, ja que esdevenen gairebé sinònims. D'altra banda, veiem que els marcadors en definitiva i en fi no poden ser substituïts en totes les ocasions per cap altre dels analitzats, perquè de vegades vehiculen d'altres instruccions no compartides pels altres marcadors, com ara l'enu- 
meració o la denominació, en el cas d'en fi o la designació, en el cas d'en definitiva. Ara bé, per parlar de sinonímia en els marcadors, ens hem de fixar també amb la resta de paràmetres per veure si també pel que fa a la jerarquia, a la polifonia i a la posició sintacticodiscursiva podrien ser substituiits els uns pels altres.

Pel que fa a la jerarquia entre els enunciats units pels marcadors s'observa una petita diferència entre el grup dels marcadors al cap i a la fi i en definitiva, d'una banda, en què l'enunciat reformulador sempre es presenta com a més important que el reformulat i, d'altra banda, el marcador en fi, que no el presenta així en totes les ocasions. Tal com hem explicat, atribuïm aquesta diferència a la composició semàntica de cada marcador. Com dèiem abans, el marcador al cap i a la fi vehicula una reformulació global del text, d'un cap a un altre, i en definitiva vehicula una reformulació que posa fi a una cosa d'una manera fixa, que no dóna lloc a tornar-hi (DIEC2). En canvi en fi introdueix una conclusió, però aquesta no es presenta necessàriament com una veritat més important que la resta d'enunciats.

En relació a la polifonia, ja hem assenyalat que és present en tots els casos analitzats, tot $\mathrm{i}$ que en algunes ocasions pugui aparèixer marcada formalment $\mathrm{i}$ en d'altres no.

Finalment volem comparar la posició sintacticodiscursiva dels marcadors que ens ocupen i per facilitar la tasca, presentem el quadre 2, resum de la posició sintacticodiscursiva dels tres marcadors analitzats:

\begin{tabular}{|c|c|c|}
\hline Posició inicial & Posició intermitja & Posició final \\
\hline al cap i a la fi & al cap i a la fi & - \\
\hline en fi & en fi & en fi \\
\hline en definitiva & - & - \\
\hline \multicolumn{3}{|c|}{ Combinabilitat amb d'altres nexes discursius } \\
\hline $\mathrm{i}$ & $()$, & $\begin{array}{l}\text { al cap i a la fi } \\
\text { en fi } \\
\text { en definitiva }\end{array}$ \\
\hline però & $()$, & $\begin{array}{l}\text { al cap i a la fi } \\
\text { en fi } \\
\text { en definitiva }\end{array}$ \\
\hline perquè & $($, $)$ & $\begin{array}{l}\text { al cap i a la fi } \\
\text { en definitiva }\end{array}$ \\
\hline
\end{tabular}

QuADRE 2. Posició sintacticodiscursiva dels marcadors objecte d'estudi d'aquest treball. 
Pel que fa a la posició en què se situen respecte al discurs, veiem que tots tres marcadors poden aparèixer en posició inicial, i que en fi és l'únic marcador dels tres que es pot presentar en posició final, posició gens habitual per als marcadors de reformulació catalans ${ }^{14}$.

Si ens referim a la combinabilitat amb d'altres marcadors, veiem que tots tres poden combinar-se amb però i amb $i$ i que el marcador en fi no cooapareix mai amb perquè.

En conclusió, al cap i a la fi i en fi poden ser considerats sinònims de en definitiva si apareixen en posició inicial o units a però i $i$. En canvi, aquesta relació de sinonímia no és bidireccional, ja que ni al cap i a la fi ni en definitiva poden ser substituïts per en definitiva, ni l'un per l'altre, perquè ni tan sols comparteixen les mateixes instruccions. Això no vol dir que en alguna ocasió no puguin ser intercanviables, però no ho serien pas en la majoria.

Per acabar volem assenyalar que seria molt interessant completar aquest estudi amb l'anàlisi d'altres marcadors conclusius com ara en el fons, o sigui o en altres paraules (també reformulatius) o en conclusió, al capdavall, total i tot plegat, de manera que poguéssim explicar globalment el fenomen de la conclusió reformulativa en català.

En realitat, les diferents puntualitzacions sobre el funcionament de marcadors similars en castellà o en altres llengües romàniques, que hem anat comentant en aquest article, demostren també la importància d'estudis contrastius interllengua que permetrien veure la influència dels components dels diferents marcadors en el seu funcionament ${ }^{15}$.

Finalment, volem assenyalar que som conscients que la validesa d'aquest estudi només és aplicable als textos escrits i que per a un estudi global del funcionament d'aquests marcadors seria necessari accedir a corpus multimodals (amb veu i imatge) que permetessin validar les conclusions a què hem arribat. Sens dubte, els darrers progressos de la tecnologia en l'anàlisi de corpus facilitaran ben aviat aquesta tasca. Al cap i a la fi, aquest article és un primer pas no definitiu ni final en l'estudi d'aquests marcadors.

\section{BIBLIOGRAFIA}

Adam, J. M.; Revaz, F. (1989): «Aspects de la structuration du texte descriptif: les marqueurs d'énumeration et de reformulation». Langue française 81. 59-98.

AlCover, A. M.; Moll, B. (1930-1962): Diccionari català-valencià-balear. Inventari lexicogràfic i etimològic de la llengua catalana, Palma de Mallorca: Alcover-Miramar.

14 De fet, a Bach (2009) comparàvem l'ús dels marcadors reformulatius parafràstics del català amb els del castellà i observàrem que mentre que en castellà dos d'aquests marcadors podien aparèixer en posició final —o sea i mejor dicho_ no n'hi havia cap que pogués ocupar aquesta posició en català.

15 Per a una anàlisi contrastiva dels marcadors reformulatius en castellà amb d'altres llengües, pot consultar-se Garcés (2009). 
Anscombre, J. C. et al. (1995): Théorie des topoï, París: Kimé.

BACH, C. (2001): Els connectors reformulatius catalans: Anàlisi i proposta d'aplicació lexicogràfica. Tesi doctoral. [Versió en CD: Barcelona: Institut Universitari de Lingüística Aplicada, Universitat Pompeu Fabra. Sèrie Tesis, 6. 2004].

BACH, C. (2009): «La reformulación del discurso español en comparación con el catalán. Estudio contrastivo de los marcadores de reformulación». A: GARCÉS. M. P. (ed.) La reformulación del discurso en español en comparación con otras lenguas. Madrid: Universidad Carlos III/BOE. 37-66.

CADIOT, A. et al. (1985): «En fin, opérateur métalinguistique», Journal of pragmatics 9. 199-239.

CuencA, M. J. (2002): «Els connectors textuals i les interjeccions». A: Solà, J. et al, [dir.]. Gramàtica del català contemporani. Barcelona: Empúries. 3173-3237.

Ducrot, O.; Anscombre, J. C. (1983): La argumentación en la lengua, Madrid: Gredos. 1994.

FRANCKEL, J. J. (1987): «Fin en perspective: finalement, enfin, à la fin». Cahiers de Linguistique Française 8. 43-69.

GARCÉs, M. P. (2003): «Los marcadores de recapitulación y de reconsideración en el discurso». Revista de Investigación Lingüística 1. Vol 6. 111-141.

GARCÉs, M. P. (2009): «La reformulación discursiva». a: Garcés. M. P. (ed.) La reformulación del discurso en español en comparación con otras lenguas. Madrid: Universidad Carlos III/BOE. 17-35.

GRIEVE, J. (1996): Dictionary of Contemporary French Connectors, Londres: Routledge.

GÜLICH, E.; KoTSCHI, T. (1995): «Discourse production in oral communication», a: Quasthoff, U. M. (ed.) Aspects of oral comunication, Research in text theory, 21. Berlín-Nova York: Walter de Gruyter. 30-66.

Institut D'Estudis CATAlans (2007): Diccionari de la llengua catalana. 2. ${ }^{\mathrm{a}}$ ed., corr. [DIEC2]. Barcelona, Palma de Mallorca, València: Ed. 3: 4, Ed. 62, Moll, Enciclopèdia Catalana, Abadia de Montserrat.

LUSCHER, J. M.; MOESCHLER, J. (1990): «Approches dérivationnelles et procédurales des opérateurs et connecteurs temporels: les exemples de et et de enfin», Cahiers de Linguistique Française, 11. 77-79.

MonTolío, E. (1992): «Los conectores discursivos: acerca de al fin y al cabo», a: Martín Vide, C. (ed.) Lenguajes naturales y lenguajes formales VIII, Barcelona: Promocions i Publicacions Universitàries. 453-460.

PORTOLÉs, J. (1998): Marcadores del discurso, Barcelona: Ariel.

RossARI, C. (1994): Les operations de reformulation: analyse du processus et des marques dans une perspective contrastive français-italien, Berna: Peter Lang.

Roulet, E. (1987a): «Complétude interactive et connecteurs reformulatifs», Cahiers de Linguistique Française 8. 111-140.

RoULET, E. (1987b): «Approche pragmatique de quelques locutions adverbiales données comme synonimes par les dictionnaires du français contemporain». Cahiers Ferdinand de Saussure 41. 177-184.

Turco, G.; Coltier, D. (1988): «Des agents doubles de l'organisation textuelle: les marqueus d'intégration linéaire». Pratiques 57. 57-79. 
VÁZQUEZ VeIGA, N. (1994): «Una aproximación a algunos marcadores con función textual de resumen, conclusión y cierre». Estudios de Lingüística de la Universidad de Alicante, 11. 349-390.

\section{Corpus d'anàlisi}

Corpus Tècnic de l'Institut Universitari de Lingüística Aplicada, Universitat Pompeu Fabra. Consulta en línia a través de BwanaNet

[HTTP://BWANANET.IULA.UPF.EDU/]. 
